\begin{tabular}{|c|c|c|}
\hline $\begin{array}{c}\text { Let's Talk Seafood: Romanian Acceptability } \\
\text { of Marine Aquaculture at a Glance } \\
\text { (Magda-Ioana Nenciu, Victor Niță, }\end{array}$ & $\begin{array}{c}\text { "Cercetări Marine“6 } \\
\text { Issue no. 51 }\end{array}$ & \\
Fabio Massa, Davide Fezzardi, & Pages 156-177 & $\mathbf{2 0 2 1}$ \\
Linda Fourdain) & & \\
\hline \multicolumn{2}{|c|}{ DOI:10.55268/CM.2021.51.156 } \\
\hline
\end{tabular}

\title{
LET'S TALK SEAFOOD: ROMANIAN ACCEPTABILITY OF MARINE AQUACULTURE AT A GLANCE
}

\author{
Magda-Ioana Nenciu ${ }^{1}$, Victor Niță ${ }^{1 *}$, Fabio Massa ${ }^{2}$, \\ Davide Fezzardi ${ }^{3}$, Linda Fourdain ${ }^{4}$
}
${ }^{1}$ National Institute for Marine Research and Development "Grigore Antipa", 300 Mamaia Blvd., 900581, Constanta, Romania,
${ }^{2}$ Senior Expert on Aquaculture, Via Massimi 35, 00136, Rome, Italy
${ }^{3}$ Senior Expert on Aquaculture, Via di Val Cannuta 32, 00166, Rome, Italy
${ }^{4}$ Aquaculture Expert, Alicante, Spain
E-mail:vnita@alpha.rmri.ro

\begin{abstract}
Despite the continuous population growth and the need for high-quality food, the social acceptance or non-acceptance of aquaculture by the inhabitants of a particular region affects the development of the sector by modulating consumption and, implicitly, profitability of this activity. In the Mediterranean and Black Sea areas, there was a rapid expansion of aquaculture after the 1990s, but regulation from a legislative point of view was much slower than the development of the sector itself, at least in the Black Sea region. The process of selecting suitable locations, as well as the allocation of zones for aquaculture (AZA), are relatively recent issues promoted by the General Fisheries Commission for the Mediterranean (GFCM). Moreover, the social acceptability of aquaculture and, implicitly, of the resulting products (shellfish and or finfish) also concerns the issues related to food safety and public health risks all the more so. In this respect, the major problem that prevented both the cultivation and harvesting of bivalves from the natural environment in Romania was the lack of a microbiological classification of Black Sea waters, as required by Regulation (EC) no. 627/2019 - an aspect finally settled in 2020 by the initial classification of all designated production and relaying areas of live bivalve mollusks - Chituc - Perișor, Mamaia Bay and Agigea - Mangalia - in class A. In this context, the attitudes and preferences of seafood consumption and the perception and acceptance of marine aquaculture in Romania were explored by developing and submitting a survey with 26 closed questions, with multiple choice answers. A total of 499 questionnaires were collected from a wide range of respondents all around the country, mainly focusing on the residents from the coastal area, but also from the rest of the country, including Bucharest. The results of the survey were analyzed, and they indicate that, in Romania, despite the environmental and administrativelegislative drawbacks (the latter partially resolved through the microbiological classification) that have hindered, so far, the development of mariculture, there is potential for enhancing social acceptability of this activity. Most respondents were open to consuming aquaculture products, considering, in total, that shellfish aquaculture can bring multiple benefits from the economic, social and environmental point of view.
\end{abstract}

Key-Words: mariculture, shellfish, social acceptability, public perception, food safety 


\section{AIMS AND BACKGROUND}

The perception of aquaculture by the general public amplifies the challenges related to the use of maritime space for this type of activity. Thus, although the continuous population growth stimulates the need for high quality food and its availability (Charles et al., 2010), the social acceptance or nonacceptance of aquaculture by the inhabitants of a certain region affects the development of the sector, by modulating, among other things, consumption and, implicitly, the profitability of this activity (Bacher et al., 2014; FAO, 2016; Thomas et al., 2017). This is especially true for countries where aquaculture is a well-established activity (Corner et al., 2020).

Marine aquaculture operations take place in common areas, where different uses co-exist, which can often become conflicting. Additional efforts are absolutely needed to enhance the "multi-use" approach, through the coexistence of all activities (Le Gouvello et al., 2017). The lack of coordination between different users of the maritime space and sectors with different objectives is increasingly likely to hinder the sustainable development of aquaculture in the Mediterranean and Black Sea (Corner et al., 2020).

Addressing the public acceptability of aquaculture as part of a complex maritime spatial planning process improves its long-term sustainability in terms of environmental, social and economic aspects (FAO, 2010). In a wider perspective, social acceptability is an important component of sustainability and reflects the stakeholders' and more in general the wider society's perception of the sector (Hishamunda et al., 2014).

Concepts such as acceptability and social responsibility have become, progressively, key factors for the development of aquaculture (Massa, 2011). These concepts can be integrated into the ecosystem approach to aquaculture (EAA), as part of a general governance structure of the sector (Corner et al., 2020). The contribution of a good governance in aquaculture as an importat element to increase social acceptability is clearly indicated in the Strategy for the Sustainable Development of Mediterranean and Black Sea Aquaculture adopted by the General Commission for Fisheries in the Mediterranean (GFCM) as Resolution GFCM/41/2017/1 at its $41^{\text {st }}$ session held in Montenegro (GFCM, 2017).

In the Mediterranean and Black Sea areas there was a rapid expansion of aquaculture after the 1990s (Massa et al., 2017), but legislative regulation was much slower than the development of the sector itself. The process of selecting suitable locations, as well as the allocation of zones for aquaculture (AZA) are relatively recent issues promoted by the GFCM, which in 2012 adopted the GFCM Resolution 36/2012/1, that provides guidelines on AZA (GFCM, 2012). The implementation of AZA takes into account the social component, which is essential to prevent adverse social interactions with aquaculture activities. 
This resolution is not binding, but acts as a basic framework to guide GFCM contracting parties in setting-up AZAs (Sanchez-Jerez et al., 2016).

At European level, within the Horizon 2020 MedAID project (Mediterranean Aquaculture Integrated Development), there was a work package dedicated to increasing the social acceptability of aquaculture (WP7: Social Acceptability and Policies for the Development of Aquaculture in the Mediterranean), given that one of the major constraints that explains the stagnation of aquaculture in Europe is low social acceptability (Cidad et al., 2018). This negative perception of aquaculture is primarily related to its image as a polluting activity (Gartzia et al., 2018). Moreover, the aquaculture sector is facing increasing competition for the use of space and resources in maritime and coastal areas with other economic and recreational activities (Stancu et al., 2018).

The MedAID project aimed, inter alia, to better understand the factors that determine the social acceptability of aquaculture based on the results of recent aquaculture development projects, but also from other economic sectors. Subsequently, this analysis was confronted with the perception of stakeholders at local, regional and international level, in dedicated workshops (MedAID Workshop on "The importance of social acceptability for Mediterranean aquaculture development“, Montpellier, France, 29 August 2018; GFCM Workshop "Guidelines in support of social acceptability of sustainable aquaculture development”, Monastir, Tunisia, 8 - 10 April 2019), and through a regional appraisal to support the identification of those critical factors underpinning the social acceptability of aquaculture. The synthesys of this work are guidelines that address governance, environmental, economic, and social and ethical aspects that could influence the social acceptability of aquaculture in the region and, for each aspect, they recommend practical actions and identify the main categories of stakeholders that should be involved (Massa \& Fezzardi, 2021).

Referring strictly to the Black Sea, the expansion of marine aquaculture depends on the availability of space for the development of this activity in a sustainable way, especially in the case of the Romanian coast, characterized by extremely restrictive environmental conditions (very few sheltered areas, storms, variable salinity and temperature). In addition, the extension of existing and the establishment of new Natura 2000 sites has been done by overlapping with pre-existing traditional economic activities, mainly fishineries, but also with other uses of the maritime space. Allocated zones for aquaculture (AZAs) are therefore considered an essential tool for the sustainable development of mariculture and have a special role in maritime spatial planning in an area as limited and crowded as the Romanian one (Niţă et al., 2020). 
The identification of an AZA results from the zoning processes through participatory spatial planning, through which the administrative bodies (in Romania, the National Agency for Fisheries and Aquaculture - NAFA) legally establish that certain areas in a region have priority for the development of aquaculture. In the case of the Romanian coast, applying the internationally established methodology (Del Castillo y Rey \& Macias, 2006; Fourdain, 2017; Macias et al., 2019), a pre-identification of a suitable area was made (Agigea Eforie), which meets all the prerequisites for the development of aquaculture without causing pressure on the environment and, at the same time, being socially accepted by all users of the maritime space (Niță et al., 2020).

Moreover, the social acceptability of aquaculture and, implicitly, of the resulting products (fish and/or shellfish) also concerns the issues related to food safety and public health risks (FAO, 2018), all the more so as the major problem that prevented both the cultivation and harvesting of bivalves from the natural environment in Romania was the lack of microbiological classification of Black Sea waters, as required by Regulation (EC) no. 627/2019 (Nenciu et al., 2020). Following the numerous interventions made by NIMRD (through the Shellfish Aquaculture Demonstrative Center - S-ADC) since June 2019, with the support of GFCM, with the National Sanitary-Veterinary Authority (ANSVSA), Constanța and Tulcea Sanitary-Veterinary Directorates, National Agency for Fisheries and Aquaculture (NAFA), the Ministry of Environment, Waters and Forests (MEWF), as well as the Institute of Diagnosis and Animal Health (IDAH), in September 2020 the microbiological survey was completed and the Competent Authority (ANSVSA) classified all 3 live bivalve mollusks production and relaying areas from the Romanian Black Sea sector (Chituc Perișor, Mamaia Bay and Agigea - Mangalia) in class A. Thus, mollusks harvested from or cultivated in these areas can be placed on the market for human consumption without further purification treatments.

Marine aquaculture in Romania is at its ancillary phase of development and, consequently, having a general undestanding on how aquaculture products and activities are perceived by the public at large is essential. Previous surveys performed in Romania indicated that, despite a slight openess of consumers towards seafood products (Zaharia et al., 2005), they are not aware of differences among wild and farmed fish/shellfish (ROMPOP, 2014). Furthermore, there seemed to be a general lack of information about sustainability (EUMOFA, 2017) and traceability issues (Nicolae et al., 2016).

In this overall context, the evaluation of consumption habits and the perception of marine aquaculture and seafood products in Romania was performed in this study by designing and submitting an online survey with multiple choice answers. 


\section{EXPERIMENTAL}

The methodology used to investigate the social acceptability of marine aquaculture and seafood in Romania was based on a survey designed on a series of questions that were selected from the available references on public perception of aquaculture activities, on the consumption of resulting products and on aquaculture and its relationship with other uses of the maritime space (Chu et al., 2010; Massa, 2011; D’Anna \& Murray, 2015; Nicolae et al., 2016; Brayden et al., 2018; Rubstello, 2019).

Based on the above was developed a survey with 26 selected questions, with multiple choice answers (in Romanian). Questions 1-5 concerned the collection of demographic data of respondents (age category, region, level of education and income). Questions 6-26 covered aspects of frequency of consumption, type of seafood products consumed, preference for fish or shellfish, opinions on price, origin of products, food safety and public health, opinions on the influence of aquaculture on the environment, and knowledge of legislation. After carefully designing the questions, the survey was transposed in electronic format using Google Docs, and subsequently submitted by e-mail and social networks to a wide range of potential respondents from all around Romania, focusing mainly on the coastal area and Bucharest. A total of 499 respondents filled-in the questions indicated in the survey and all the replies were subsequently organized in a database, analyzed and the results were finally commented.

The additional explanatory factors that may influence the perception of a respondent could be the distance between their residence and the coast, as well as the awareness about aquaculture, other than those factors considered in the survey (Alexander et al., 2016; Thomas et al., 2018). For the statistical analysis of the answers, an ordinal logistic regression was used to predict the behaviour of an ordinal dependent variable according to independent variables. In this case, the ordinal regression was performed to determine whether selected independent variables of the respondent (age, level of awareness about aquaculture, distance of residence from the coast, seafood eating frequency and whether the respondents visited or saw marine aquaculture farms) could predict respondents' perception. The question tested was "What is your opinion about the impact of shellfish aquaculture on the marine environment?". The answers were grouped, classified and finally treated as a 4-point Likert item (Chang, 2004), but in this case, from "Do not know", "Negative impact", "It has no significant influence" and "Positive impact" possible answers. In order to determine the effect of awareness and knowledge level on aquaculture, respondents were sorted into low, medium and high awareness groups aiming at evaluating the correlation with their perception of aquaculture. The respondents were classified according to the combination of their responses of two questions (Table 1). 
Table 1. Respondents' level of awareness in relation to their opinion about the impact of shellfish aquaculture on the marine environment.

\begin{tabular}{|c|c|c|c|}
\hline Question & \multicolumn{3}{|c|}{ Answers } \\
\hline $\begin{array}{l}\text { "Regarding the } \\
\text { environmental impact, } \\
\text { compared to finfish } \\
\text { aquaculture, do you } \\
\text { consider that shellfish } \\
\text { aquaculture is:" }\end{array}$ & $\begin{array}{l}\text { Do not know / } \\
\text { More harmful to } \\
\text { the environment }\end{array}$ & $\begin{array}{l}\text { Do not know / } \\
\text { More } \\
\text { environmentally } \\
\text { friendly / They have } \\
\text { a similar impact }\end{array}$ & $\begin{array}{c}\text { More } \\
\text { environmentally } \\
\text { friendly }\end{array}$ \\
\hline $\begin{array}{l}\text { "What is your opinion } \\
\text { about the impact of } \\
\text { shellfish aquaculture on } \\
\text { the marine } \\
\text { environment?" }\end{array}$ & $\begin{array}{l}\text { Do not know / } \\
\text { Negative impact }\end{array}$ & $\begin{array}{c}\text { Do not know / It } \\
\text { has no significant } \\
\text { influence / Negative } \\
\text { impact / Positive } \\
\text { impact }\end{array}$ & Positive impact \\
\hline Level of awareness & Low & Medium & High \\
\hline Number of respondents & 183 & 201 & 115 \\
\hline
\end{tabular}

\section{RESULTS AND DISCUSSION}

\section{Data results distribution by category and questions}

Regarding the age distribution of the respondents (Fig. 1), the majority (44\%) were in the range of 40-60 years, followed by those aged 25-40 years (38\%), those under 25 and over 60 registering a similar response rate (9\%). From a geographical distribution point of view (Fig. 2), most of respondents (56\%) stated that they live in the Black Sea coastal area, having much easier access to products of this type, followed by those in Bucharest, Romania's capital city (29\%). Only $15 \%$ of respondents came from other areas of the country, where seafood is less known and/or appreciated.

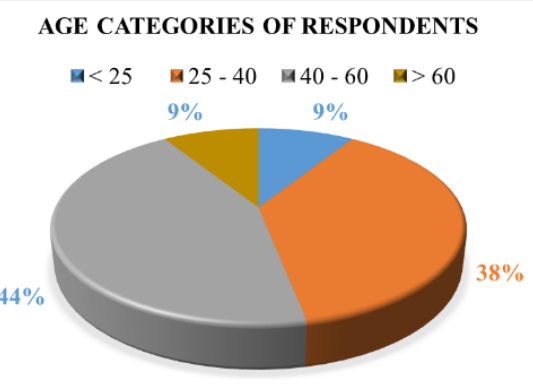

Fig. 1. Age categories of survey respondents

\section{RESIDENCE REGION OF RESPONDENTS}

Bucharest $\square$ Black Sea coast $\mathbf{a}$ Rest of the country

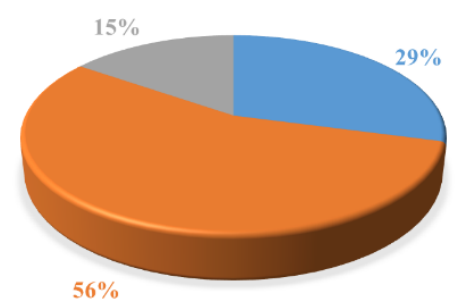

Fig. 2. Respondents'geographical area of residence 
The distribution of respondents in terms of housing in urban or rural areas (Fig. 3) was clearly in favor of the urban environment (89\%), only $11 \%$ of them coming from rural areas, an aspect perfectly explainable by the much higher availability of this type of products in cities (restaurants, hypermarkets, shopping malls etc.). In terms of the level of education (Fig. 4), most respondents stated that they have higher education, namely university degrees (47\%) and postgraduate studies (41\%), respectively, only $12 \%$ of them having secondary (high school) education.

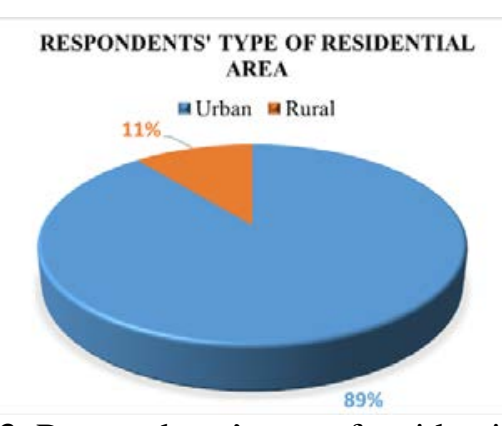

Fig. 3. Respondents' type of residential area (urban vs. rural)

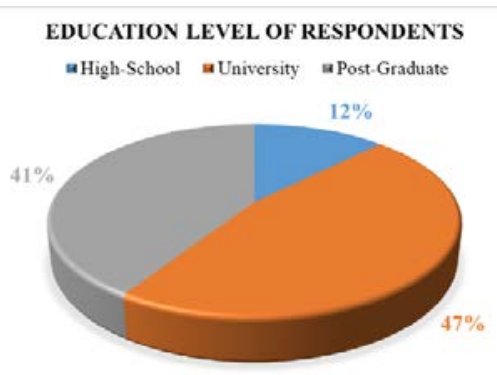

Fig. 4. Education level of survey respondents

Regarding the level of monthly income of respondents (Fig. 5), the range with the most respondents (41\%) was between 600 - 1,000 Euro, followed by those with incomes below 600 Euro (30\%) and those with incomes between 1,000 - 1,600 Euro (18\%). Those with high incomes (over 1,600 Euro) totaled only $11 \%$ of the survey respondents.

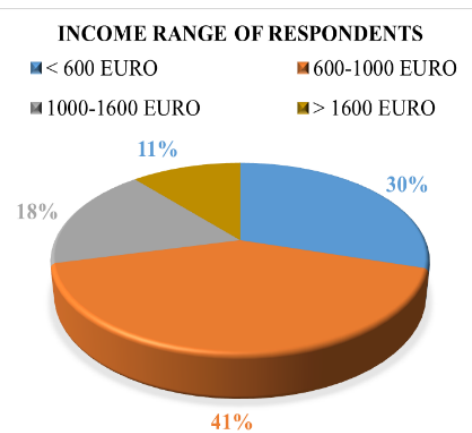

Fig. 5. Respondents' monthly income range
TYPES OF SEAFOOD EATEN BY RESPONDENTS

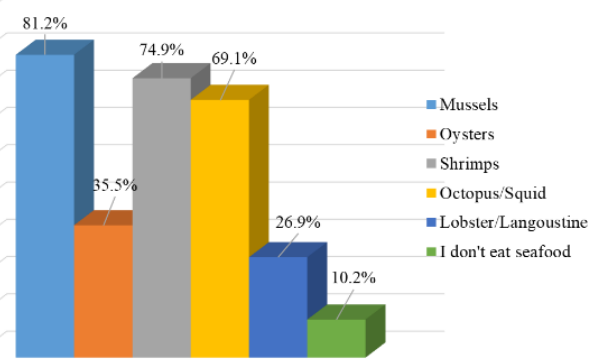

Fig. 6. Types of seafood eaten by survey respondents

In terms of the types of seafood consumed (Fig. 6), most respondents stated that they ate mussels (81.2\%), followed by shrimps $(74.9 \%)$ and octopus/squid (69.1\%). Oysters were consumed by only $35.5 \%$ of the 
respondents to the questionnaire, while $26.9 \%$ also tried lobster/langoustine. $10.2 \%$ of those who completed the questionnaire stated that they do not eat seafood.

Concerning the frequency of seafood consumption (Fig. 7), most respondents stated that this type of product is consumed occasionally (70\%), only $21 \%$ consuming seafood often. The percentage of those who said they never eat seafood was $9 \%$.

From the point of view of the preference for finfish or shellfish (Fig. 8), $46 \%$ of the respondents expressed their predilection for fishery products, shellfish being preferred by $34 \%$. $17 \%$ of respondents did not express a preference, while only $3 \%$ said they do not consume such products at all.

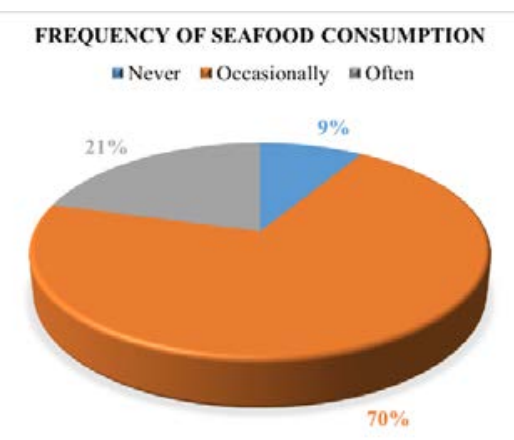

Fig. 7. Respondents' frequency of seafood consumption

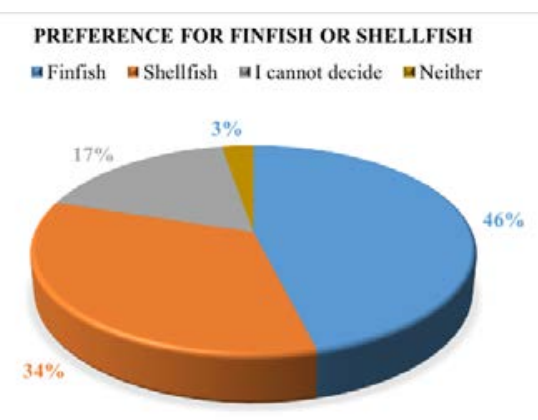

Fig. 8. Survey respondents' preference for finfish or shellfish

Regarding the preferred ways of eating finfish/shellfish (Fig. 9), home cooking met the most options (47.1\%), their consumption at the restaurant or at the traditional fishery tavern registering similar percentages $-45.7 \%$ and $45.1 \%$, respectively. $19.2 \%$ of the respondents stated that they are indifferent, and 3.4\% that they do not eat seafood and/or fish. The price of seafood (Fig. 10) was considered acceptable occasionally by more than half of the respondents (51\%), while $30 \%$ consider that it is very high in relation to their income. Only $6 \%$ of those who completed the questionnaire rated the price of seafood in Romania as fair, while $13 \%$ said they do not know.

Regarding the willingness to try more unconventional seafood products (Fig. 11), 39\% of the respondents stated that they would definitely consume live oysters, seaweed or sea whelks, and 36\% stated that they would try certain products of this type occasionally. Only $25 \%$ of respondents categorically rejected this perspective.

When asked whether or not they have concerns about food safety (Fig. 12 ), $67 \%$ of respondents said they do not, provided the existence of veterinary certifications, and $15 \%$ said they have no kind of restraints. $18 \%$ of the 
questionnaire respondents stated that they had some concerns related to seafood consumption safety, which were detailed in the next open question ("If the previous answer was YES, please bring arguments on this issue").

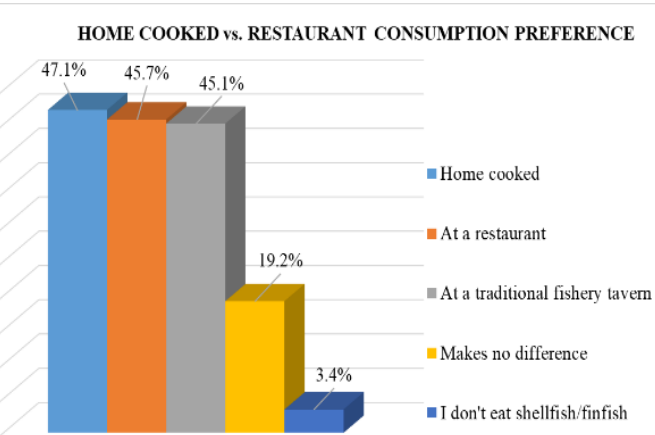

Fig. 9. Consumption preference of seafood (homecooked vs. restaurant)

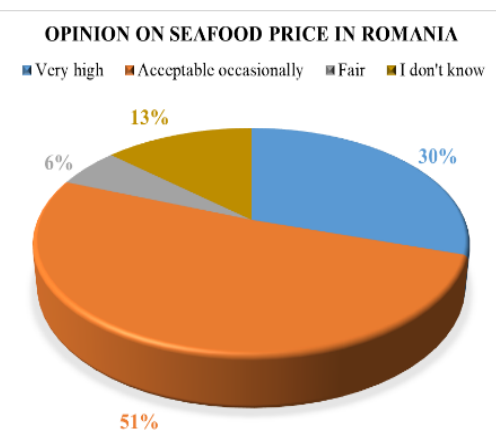

Fig. 10. Respondents' opinion about seafood prices in Romania

When asked whether or not they have concerns about food safety (Fig. 12), $67 \%$ of respondents said they do not, provided the existence of veterinary certifications, and $15 \%$ said they have no kind of restraints. $18 \%$ of the questionnaire respondents stated that they had some concerns related to seafood consumption safety, which were detailed in the next open question ("If the previous answer was YES, please bring arguments on this issue").

The main arguments put forward for reluctance to seafood consumption were the following:

- the belief that there are no adequate sanitary controls (distrust in the institutions with control attributions);

- doubts as to the provenance and freshness of the products;

- the conditions of harvesting and storage until consumption, their transport and preservation;

- potential contamination with pollutants (heavy metals and other harmful substances) by bioaccumulation;

- bacterial contamination of seafood, with a major impact on human health and food safety;

- potential infestation with parasites;

- non-compliance with the hygienic-sanitary norms at harvest and later in hypermarkets/hospitality units;

- lack of trust in processors - doubts about preparation hygiene;

- personal history of food poisoning.

Among the public health threats related to seafood consumption (Fig. 13), most respondents identified heavy metal contamination (70.9\%), followed by toxins (35.4\%), Escherichia coli and Salmonella spp., with $31.2 \%$ of the 
answers) and hydrocarbons (16.8\%). Only 19.4\% of respondents said they had no knowledge of this issue. With reference to the acceptance/non-acceptance of the consumption of shellfish collected from the natural environment or from artisanal aquaculture facilities without sanitary-veterinary documents (Fig. 14), most respondents stated that they would not consume such products without certifications (69\%), only $31 \%$ of them being willing to take risks.

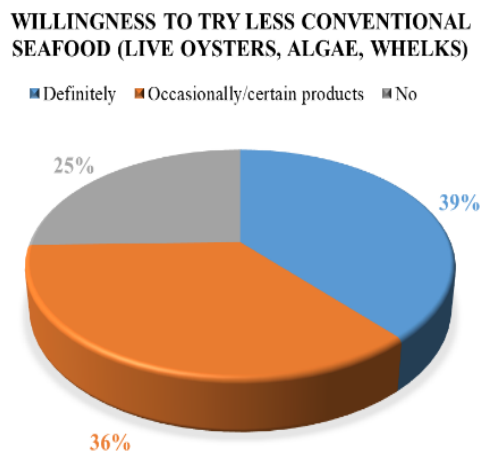

Fig. 11. Survey respondents’ willingness to try less conventional seafood products

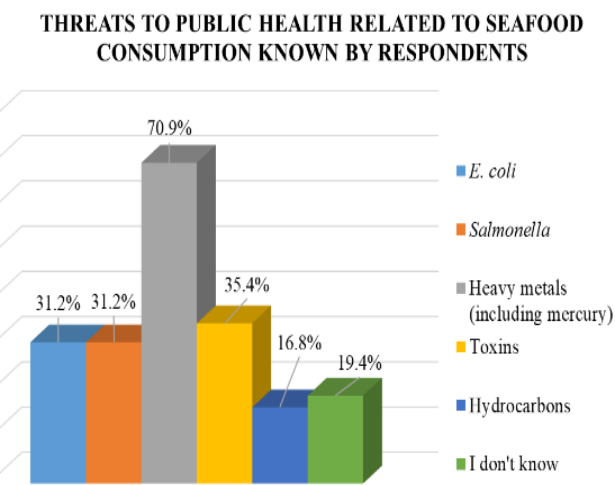

Fig. 13. Threats to public health related to seafood consumption known by respondents

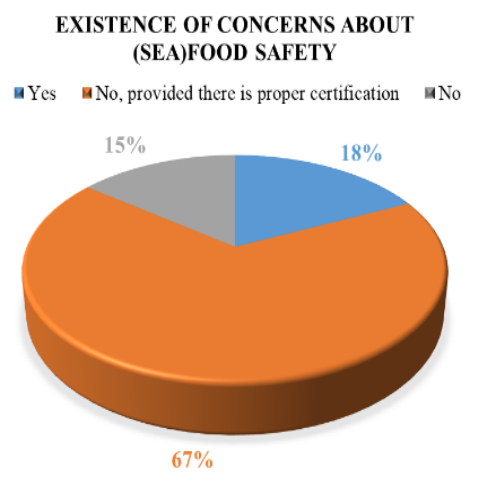

Fig. 12. Respondents' view on concerns about the safety of seafood consumption

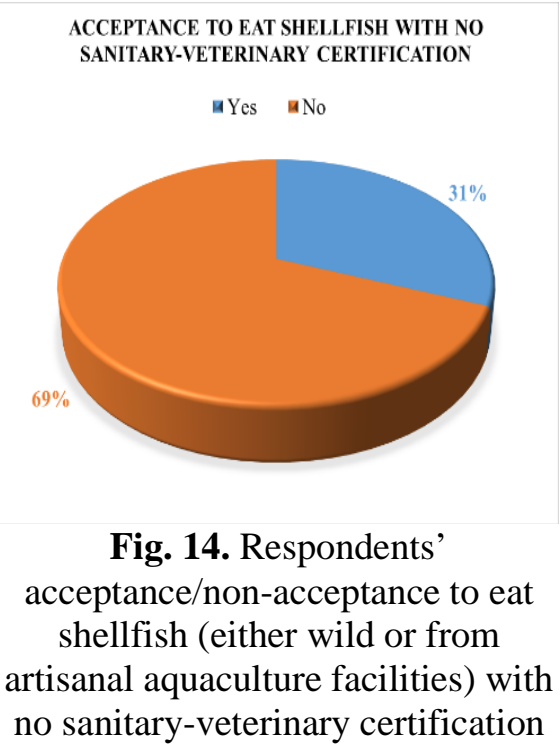

Regarding the importance of knowing the origin of the seafood consumed (Fig. 15), 60\% of the respondents stated that this aspect is very important, and 30\% - relatively important. Only 4\% of those who completed the questionnaire said they were indifferent, while 6\% mentioned that they do not consume such products. 
Also related to the origin of fishery/seafood products (Fig. 16), the harvesting/fishing from the natural environment were clearly preferred by the respondents, fish caught from the natural environment being in the top of preferences (87.6\%), followed by shellfish harvested from the natural environment (69.7\%). Aquaculture products enjoy moderate consumer confidence, whether it is shellfish (44\%) or fish (41.5\%).

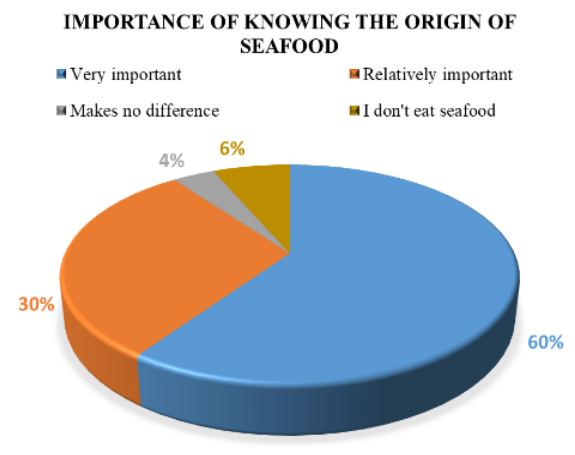

Fig. 15. Importance of knowing the origin of seafood (wild vs. aquaculture)

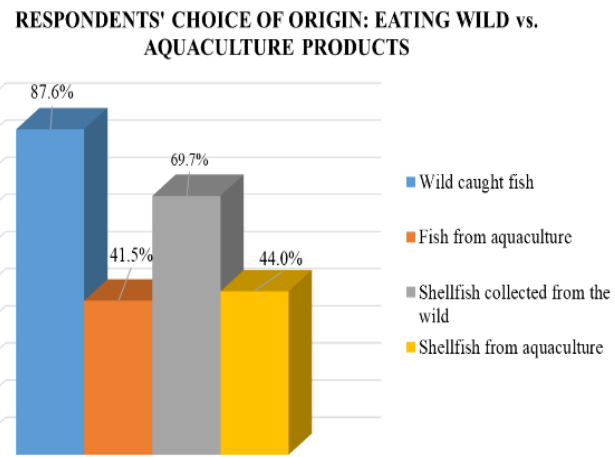

Fig. 16. Respondents' choice of consuming wild finfish/ shellfish vs. from aquaculture

Regarding the respondents' knowledge on the environmental impact of shellfish aquaculture compared to that of finfish (Fig. 17), most of them stated that they do not know (44\%). 34\% of respondents said that shellfish aquaculture is more environmentally friendly, $20 \%$ that it has a similar impact, while only $2 \%$ of respondents consider it more harmful.

Detailing the opinion of the respondents regarding the influence of shellfish aquaculture on the quality of the marine environment (Fig. 18), most of them stated that they do not know (44.8\%), 33.5\% stating that it improves water quality. $16.5 \%$ of respondents consider that it does not have a significant influence, while $6.2 \%$ believe that it affects wild species and $2.4 \%$ that it is polluting.

Concerning the direct contact of the respondents with a marine aquaculture farm (Fig. 19), only 36\% of them stated that they had seen or visited such a facility, while $64 \%$ did not have a such an experience. Asked what type of shellfish farm they consider to be preferable to develop on the Romanian coast (Fig. 20), most respondents opted for small/family-owned/artisanal farms (46\%), 39\% for both types, while only $6 \%$ leaned for large farms and $9 \%$ of respondents said they did not know.

Among the socio-economic advantages that shellfish farms can bring (Fig. 21), most of the respondents indicated that they generate income for local communities (87.4\%) and jobs (86.4\%), $73.5 \%$ of them consider that it is a 
source of food with high nutritional value, and $61.7 \%$ believe that shellfish farms can increase the tourist attractiveness of a coastal area.

Only $4 \%$ of those surveyed said they did not know. Regarding the relationship between marine aquaculture and small-scale fisheries (Fig. 22), most respondents believe that these activities can complement each other, 29.3\% considering that, through professional retraining, human resources can be easily distributed between those two. $28.3 \%$ of those who completed the questionnaire believe that their simultaneous development reduces the pressure on living resources and the ecosystem, only $7.6 \%$ of respondents consider that marine aquaculture and fisheries are competitive activities. $20.2 \%$ of respondents said they did not know.

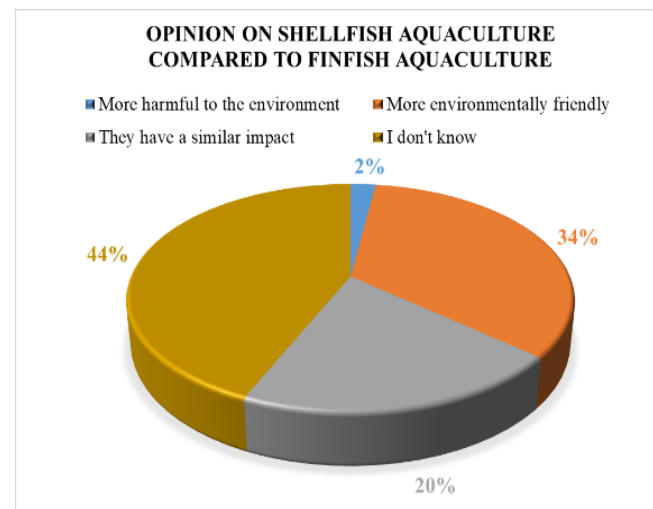

Fig. 17. Survey respondents' opinion about the environmental impact of shellfish aquaculture compared to finfish aquaculture

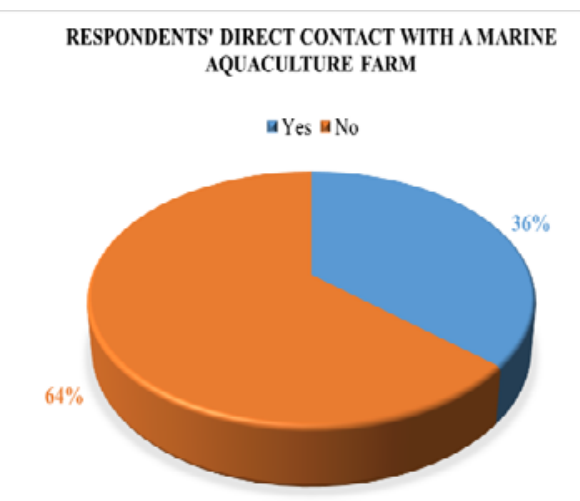

Fig. 19. Respondents' direct contact (or not) with a marine aquaculture farm

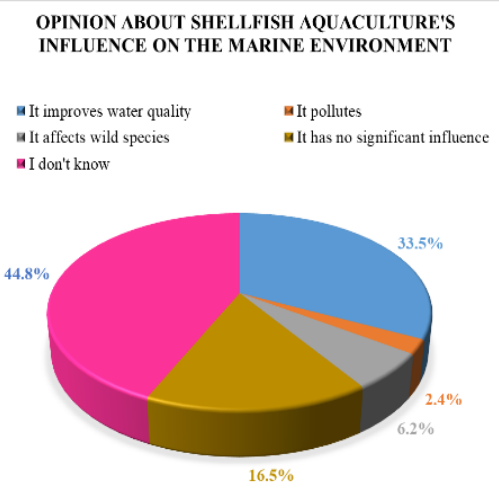

Fig. 18. Survey respondents' opinion about the impact of shellfish aquaculture on the marine environment

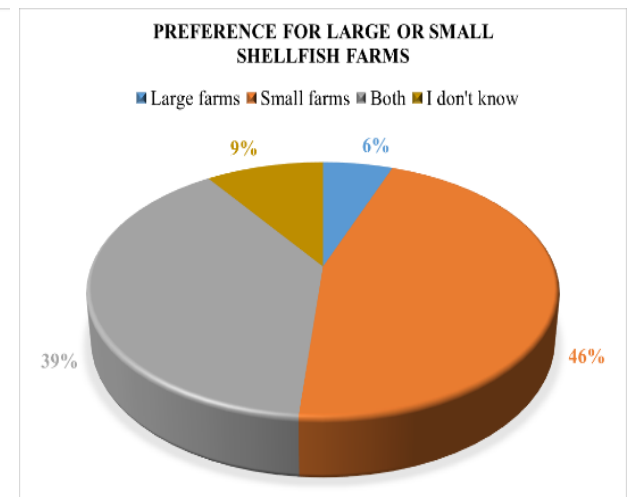

Fig. 20. Survey respondents' preference for large/industrial/ mechanized or small/artisanal/ family-owned shellfish farms 


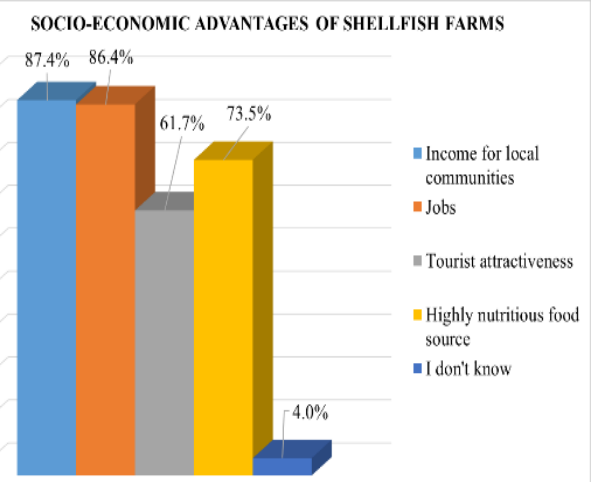

Fig. 21. Considerations on the socioeconomic advantages of shellfish farms

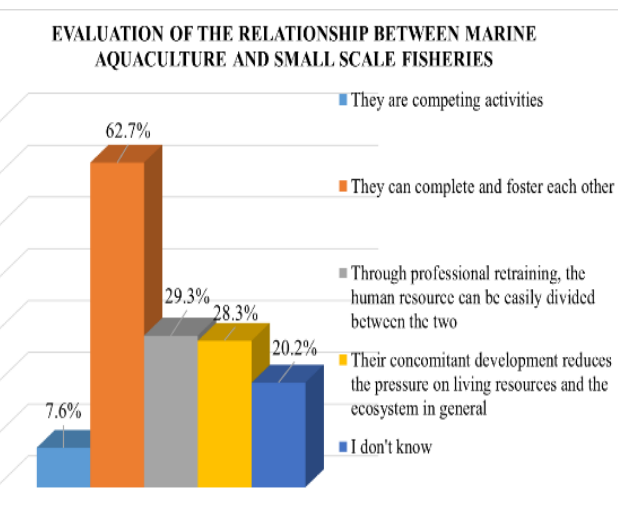

Fig. 22. Respondents' evaluation of the relationship between marine aquaculture and small-scale fisheries in Romania

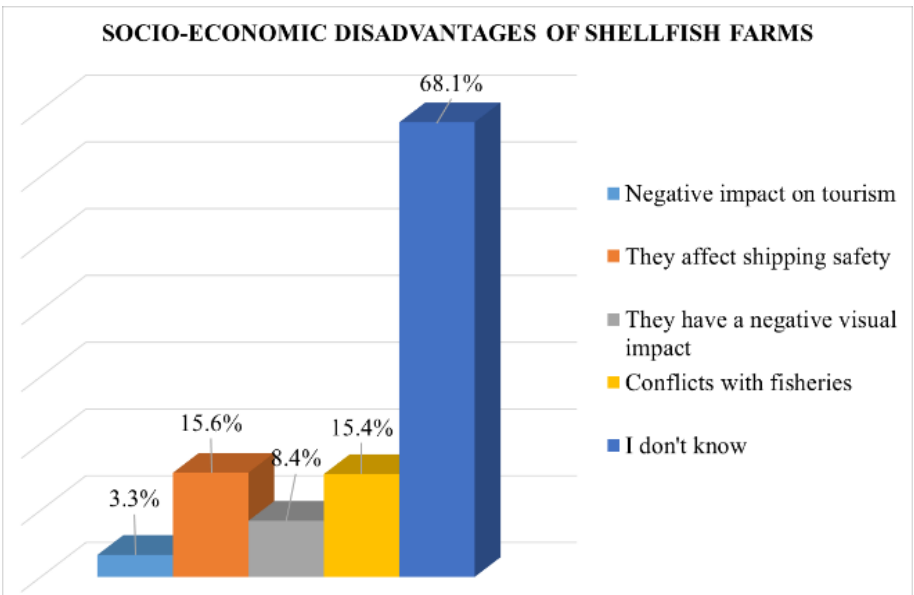

Fig. 23. Considerations on the socio-economic disadvantages of shellfish farms

When asked to indicate the socio-economic disadvantages that shellfish farms can cause (Fig. 23), most respondents stated that they do not know (68.1\%). Approximately equal percentages of respondents believe that they may affect shipping safety (15.6\%) and conflict with fishery activities (15.4\%). 8.4\% of those surveyed believe that shellfish farms have a negative visual impact, while only 3.3\% believe that they can have a negative impact on tourism.

Regarding the number of economic operators working in the field of mariculture in Romania (Fig. 24), most respondents said they had no knowledge (59\%). Only 14\% indicated the actual answer, namely none, while $16 \%$ consider that there are between 1 and 5, 6.4\% more than 10 operators and $5.2 \%$ between 5 and 10 . With reference to the legislation governing marine aquaculture and marketing of the resulting products in Romania (Fig. 25), half of the respondents stated that they have no knowledge in this regard, while 33\% believe that it needs 
to be improved, and $14 \%$ that it needs to be radically changed and $1 \%$ that it has minor gaps. Only $2 \%$ of respondents believe that the relevant legislation is complete and applicable.

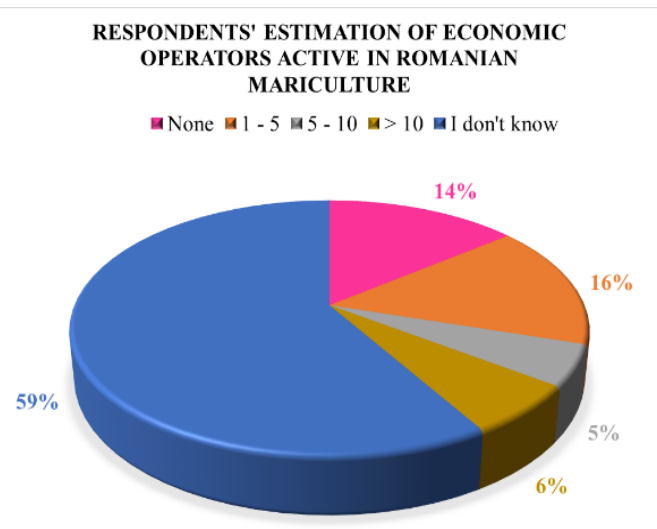

Fig. 24. Respondents' knowledge on the number of economic operators active in shellfish farming in Romania

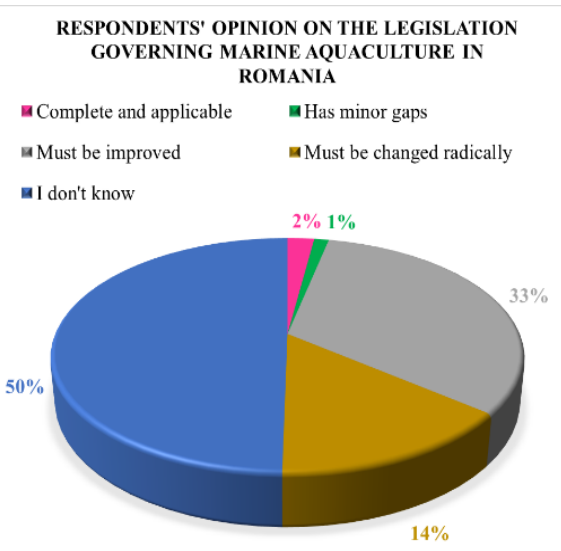

Fig. 25. Respondents' opinion on the legislation governing marine aquaculture in Romania

\section{Perception of shellfish farming}

In order to make a more in-depth analysis, the effect of variables (age, level of awareness about aquaculture, distance of residence from the coast, seafood eating frequency and whether the respondents visited or saw marine aquaculture farms) on shellfish farming perception were tested. The question "What is your opinion about the impact of shellfish aquaculture on the marine environment?" was selected to perform the analysis.

The ordinal logistic regression result for this question is summarized in Table 2 below, where only statistically significant variables appear (there were no significant differences in relation to the age of respondents). Analyzing these results, it seems that respondents answered differently according to their level of awareness about aquaculture, their seafood eating frequency, their residential distance from the coastline and if they have ever seen or visited a marine aquaculture farm.

Moreover, according to the results in Table 2 and Fig. 26, respondents with a high level of awareness about aquaculture considered that aquaculture has a positive impact on the environment to a greater extent compared to those with low and medium level of awareness (who mostly answered that they do not know). 
Table 2. Results from the ordinal logistic regression to evaluate the perception about aquaculture according to different variables

\begin{tabular}{|lllll|}
\hline Variables & $\begin{array}{l}\text { Coefficients } \\
\text { Log-odds }\end{array}$ & $\begin{array}{l}\text { Standard } \\
\text { errors }\end{array}$ & t-values & p-values \\
\hline Level of awareness & & & & \\
\hline Low & -30.19250 & 0.31281 & -96.517 & $0^{*}$ \\
\hline Medium & -25.66983 & 0.244377 & -105.041 & $0^{*}$ \\
\hline High & 0 & & & $0 *$ \\
\hline Distance from the coast & & & \\
\hline Near & 1.200791 & 0.2605964 & 4.60786 & $4.07 \mathrm{e}-06^{*}$ \\
\hline Far & 0 & & & $0 *$ \\
\hline Frequency of eating seafood & & & & $0 *$ \\
\hline Never & 0 & & & $3.542 \mathrm{e}-02^{*}$ \\
\hline Occasionally & -0.88508 & 0.4207692 & -2.10348 & $4.391 \mathrm{e}-01^{*}$ \\
\hline Often & -0.39124 & 0.5056303 & -0.77378 & \\
\hline See/visit an aquaculture farm & & & & $1.608 \mathrm{e}-02^{*}$ \\
\hline No & 0 & & & \\
\hline Yes & 0.5095836 & 0.2762527 & 1.8446286 & $6.509 \mathrm{e}-02^{*}$ \\
\hline
\end{tabular}

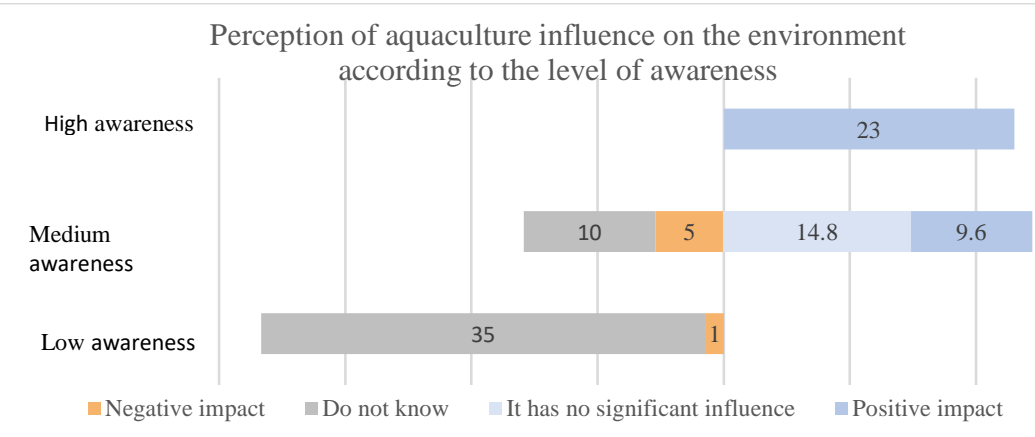

Fig. 26. Respondents' perception of aquaculture influence on the environment according to their level of awareness about the industry

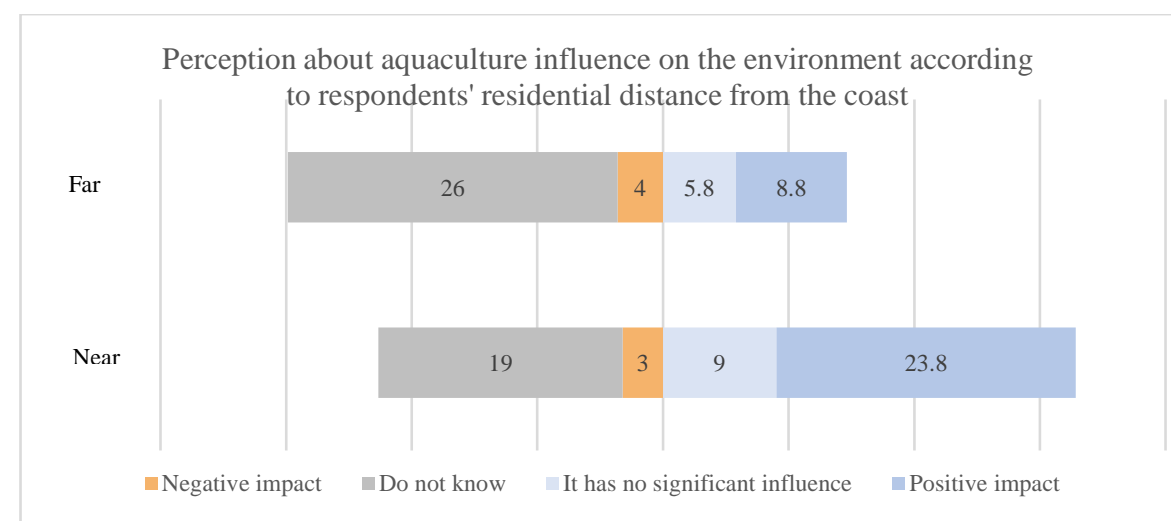

Fig. 27. Respondents' perception of aquaculture influence on the environment according to the distance between their residence and the coast 


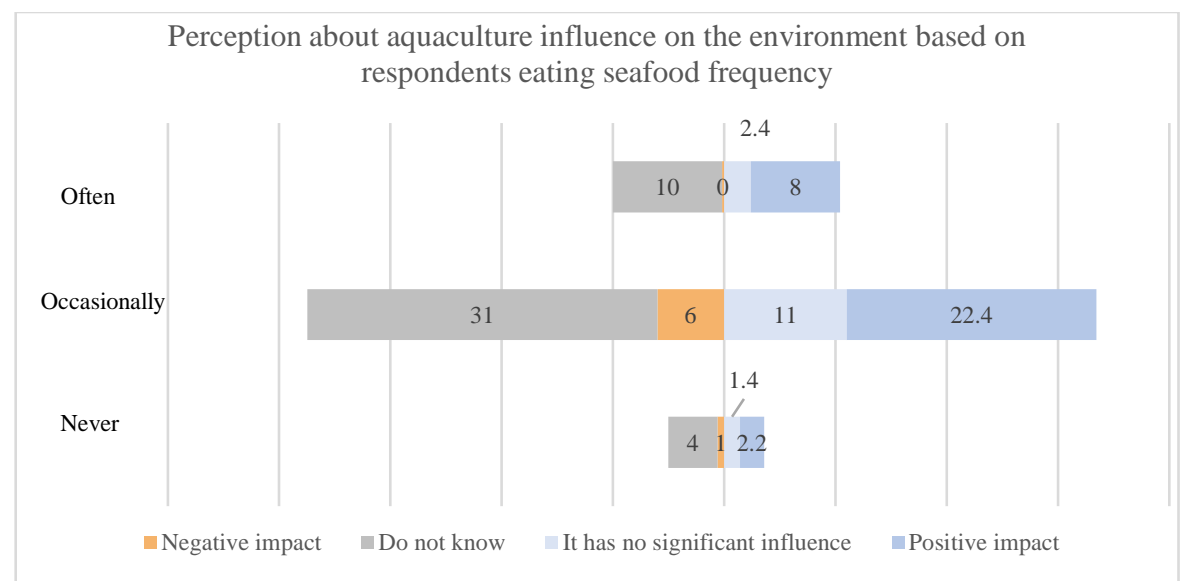

Fig. 28. Respondents' perception of aquaculture influence on the environment based on seafood eating frequency.

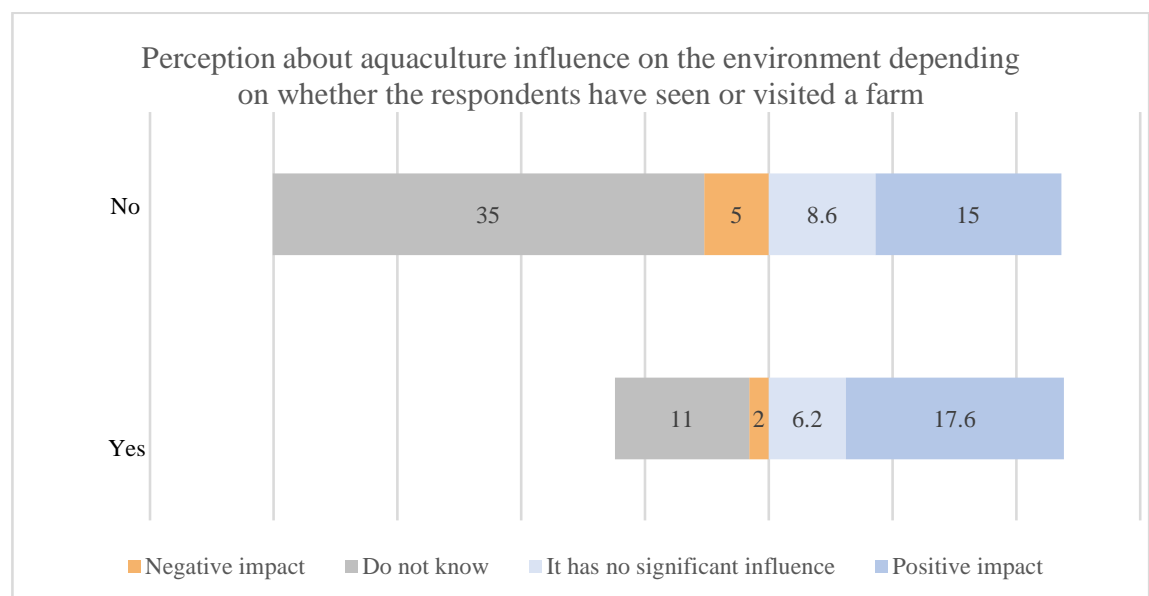

Fig. 29. Respondents' perception of aquaculture influence on the environment depending on whether the respondents have seen or visited a farm

In a similar manner, respondents who lived near the coast appraised that aquaculture has a positive influence on the marine environment more than those who live farther away (Fig. 27). A higher frequency of consumption of seafood also generated more positive answers compared to the replies of respondents who declared that they never eat seafood (Fig. 28). Finally, respondents who had a direct contact with a marine aquaculture farm gave significantly more positive answers regarding the environmental impact compared to those who have never seen a fish/shellfish farm (Fig. 29). All these findings clearly indicate that familiarity to marine aquaculture in general shapes a positive attitude and perception. 


\section{CONCLUSIONS}

In Romania, there have been attempts by companies interested in cultivating both native mussels and non-indigenous triploid oysters in small offshore installations, and turbot in recirculating aquaculture systems on land. However, the lack of legislation (also including the lack of microbiological classification of coastal waters until 2020, the still pending issue of water concession) and a scarcity of funds for investments have led to stagnation in the marine aquaculture business.

Currently, there is at least one private investor who intends to develop a shellfish farm in the Agigea area, so the acceptability of such an activity has become a topical issue, especially given the multiple uses of maritime space in that area. The suitability of the area for aquaculture was demonstrated by a high degree of compatibility (both for shellfish and finfish), which was calculated taking into account a series of environmental and socio-economic parameters, without addressing, however, the aspects related to the social acceptability of such an activity.

In this context, the results of the survey carried out provide some useful elements that could help to gain a better understanding about the perception and level of knowledge of the Romanian public regarding mariculture and its products, and their appraisal for the potential development of this sector, summarized below.

From a demographic point of view, most respondents come from the coastal area and the urban environment, which explains their familiarity with seafood, compared to those in the rest of the country. The level of education of respondents is high (university and post-university), just over $10 \%$ of them with secondary education. The majority age range was between 40 and 60 years, and the monthly income level mainly between 600 - 1,000 euro, which justifies the opinion according to which the price of seafood in Romania is acceptable only occasionally, their frequency of consumption being also occasional.

Regarding the type of seafood consumed by Romanians, mussels rank on the first place of preferences, followed by shrimps and octopus/squid (obviously imported). However, according to the answers collected, finfish are still preferred in favor of shellfish. Most respondents prefer to cook these products at home, but many also choose to consume them at the restaurant/ traditional fish tavern. The answers to the questionnaire also provided indications regarding the willingness of Romanian consumers to try less conventional products (algae, whelks, live oysters etc.).

Regarding the main concerns related to the consumption of seafood, the collected responses showed that the potential contamination with heavy metals, toxins, E. coli or Salmonella spp. are serious concerns, especially in the absence of sanitary-veterinary analysis bulletins, certifying both the provenance and the quality of the products. Moreover, the preference of Romanian respondents for 
wild products (both fish and seafood) compared to those from aquaculture is obvious, in full accordance with the distrust that is still manifested worldwide, justified by reasons related, on the one hand, to the belief that the taste and nutritional quality of those raised in a controlled environment are not as good as in the wild, and, on the other hand, to the fear of using antibiotics, hormones etc.

From the perspective of the relationship of marine aquaculture with the environment, most respondents either do not know details or consider that shellfish farming is more friendly compared to that of finfish, contributing to improving water quality. The respondents also indicated that shellfish farms bring about a number of socio-economic benefits, the most significant being the creation of income and jobs for local communities. According to the answers collected, for the Romanian coast small artisanal type farms would be preferable, which would not represent a competition for small-scale fisheries.

From the point of view of the socio-economic disadvantages that shellfish farms could cause, while in Western Europe or North America the main concern is the negative visual impact and, implicitly, its influence on tourism, respondents in Romania indicated shipping safety as the main cause for concern, most of those who completed the survey declaring, however, that they do not know these aspects. The ignorance or lack of information was also invoked regarding the number of economic operators in the field of marine aquaculture, as well as the legislation governing mariculture and the marketing of the resulting products in Romania.

In conclusion, based on the answers provided by respondents, the results show that there is a general positive attitude in accepting seafood products and in particular that shellfish and finfish are more and more accepted, both in restaurants and at home. Although there are some concerns on the control of public health aspects, yet aquaculture is considered an opportunity for Romania in terms of employment and new income, as well as environmental benefits. What is clear is that an effort still needs to be done in terms of governance and administrative-legislative aspects and monitoring system. Finally, the improvement of social acceptability of aquaculture based also on the above aspects is a fundamental issue to be considered in order to unlock the potentiality of marine aquaculture in Romania.

Acknowledgement. This work has been carried-out with financial support from the NUCLEU INTELMAR Programme, funded by the Romanian Ministry of Research, Innovation and Digitization, project no. PN 19260301, and the GFCM, through the Shellfish Aquaculture Demonstrative Center in the Black Sea (S-ADC). 


\section{REFERENCES}

Alexander K.A., Freeman S., Potts T. (2016), Navigating uncertain waters: European public perceptions of integrated multi trophic aquaculture (IMTA). Environmental Science and Policy: 61: 230-237.

Bacher K., Gordoa A., Mikkelsen E. (2014), Stakeholders' perception of marine fish farming in Catalonia (Spain): a Q-methodology approach. Aquaculture: 424: 7-85.

Brayden C.W., Noblet C.L., Evans K.S., Rickard L. (2018), Consumer preferences for seafood attributes of wildharvested and farm-raised products. Aquaculture Economics \& Management: 22(3):362-382, DOI: 10.1080/13657305.2018.1449270.

Chang L. (1994), A psychometric evaluation of 4-point and 6-point Likert-type scales in relation to reliability and validity. Applied Psychological Measurement: 18(3): 205-215.

Charles H., Godfray J., Beddington J.R., Crute I.R., Haddad L., Lawrence D., Muir J.F., Pretty J., Robinson S., Thomas S.M., Toulmin C. (2010), Food security: the challenge of feeding 9 billion people. Science: 327: 812-818.

Chu J.J., Anderson J.L., Asche F., Tudur L. (2010), Stakeholders' perceptions of aquaculture and implications for its future: a comparison of the USA and Norway. Marine Resource Economics: 25 (1): 61-76.

Cidad M., Peral I., Ramos S., Basurco B., López-Francos A., Muniesa A., Cavallo M., Pérez J., Aguilera C., Furones D., Reverté C., SanjuanVilaplana A., Brun E., Jansen M.D., Tavornpanich S., Raux P., Baraibar E., Cobo A., Fernández-Polanco J.M., Llorente I., Fernández Sánchez J.L., Luna M., Luna L., Odriozola M., Gulzari B., Janssen K., Komen H. (2018), Assessment of Mediterranean aquaculture sustainability. Deliverable 1.2 of the Horizon 2020 project MedAID (GA number 727315), published in the project web site on 21.12.2018: http://www.medaid-h2020.eu/index.php/deliverables/

Corner R.A., Aguilar-Manjarrez J., Massa F., Fezzardi D. (2020), Multistakeholder perspectives on spatial planning processes for mariculture in the Mediterranean and Black Sea. Reviews in Aquaculture: 12: 347 - 364, DOI:10.1111/raq.12321

D’Anna L. M., Murray G. (2015), Perceptions of shellfish aquaculture in British Columbia and implications for well-being in marine social-ecological systems. Ecology and Society: 20(1):57.

Del Castillo y Rey F., Macias J.C. (2006), Zonas de interés para el desarrollo de la acuicultura en el litoral andaluz. Junta de Andalucía. Consejería de Agricultura y Pesca, ISBN 84-690-1933-3: 485 pp.

EUMOFA (2017). EU consumer habits regarding fishery and aquaculture products. Mapping and analysis of existing studies on consumer habits: 78 pp. 
European Union (2019), Regulation no. 627/2019 of 15 March 2019 laying down uniform practical arrangements for the performance of official controls on products of animal origin intended for human consumption in accordance with Regulation (EU) 2017/625 of the European Parliament and of the Council and amending Commission Regulation (EC) No 2074/2005 as regards official controls.

FAO (2010), Aquaculture Development. 4. Ecosystem Approach to Aquaculture. FAO Technical Guidelines for Responsible Fisheries No. 5, Suppl. 4. FAO, Rome. Available from URL www.fao.org/docrep/013/i1750e/i1750e00.htm

FAO (2016), The state of world fisheries and aquaculture 2016: contributing to food security and nutrition for all. Rome, 200 pp. Available from URL http://www.fao.org/3/a-i5555e.pdf

FAO (2018), Food and Agriculture Organization of the United Nations. GLOBEFISH - Analysis and information on world fish trade. Available from URL http://www.fao.org/in-action/globefish/fisheryinformation/resourcedetail/en/c/379676/

Fernández Polanco J.M., Collado J., García De Los Salmones M.M., Herrero A., Pérez A., San Martín H., Llorente I., Avdelas L., Cozzolino M., Bougouss N., Luna M., Cobo A., Baraibar E., Odriozola M.D., Fernández Sánchez J.L., Luna L., Shen N. (2020), Attitudes, communication and prices. Deliverable 6.3 of the Horizon 2020 project MedAID (GA number 727315), published in the project website on 07.05.2020: http://www.medaid-h2020.eu/index.php/deliverables/

Fourdain L. (2017), Establishment of an Allocated Zone for Aquaculture (AZA) within Marine Spatial Planning in Monastir, Tunisia. Alicante, Spain, University of Alicante (MA thesis). Available at: https://rua.ua.es/dspace/handle/10045/78072

Gartzia I., Peral I., Alfaro B., Riesco S., Santa-Cruz E., Krystallis A., Brunso K., Stancu V., Claret A., Guerrero L. (2018), Identification of product and market requirements of aquaculture chain stakeholders. Deliverable 5.1 of the Horizon 2020 project MedAID (GA number 727315), published in the project web site on 21.06.2018: http://www.medaidh2020.eu/index.php/deliverables/

GFCM (2012), Resolution GFCM/36/2012/1 on Guidelines on Allocated Zones for Aquaculture (AZA). Available at http://bit.ly/Resolution-GFCM-362012-1

GFCM (2017), Resolution GFCM/41/2017/1 on a strategy for the sustainable development of Mediterranean and Black Sea aquaculture. Available at https://gfcm.sharepoint.com/CoC/Decisions\%20Texts/RESGFCM_41_2017_1-e.pdf 
Hishamunda N., Ridler N., Martone E. (2014), Policy and governance in aquaculture: lessons learned and way forward. FAO Fisheries and Aquaculture Technical Paper No. 577. Rome, FAO: 59 pp.

Le Gouvello R., Hocart L.-E., Laffoley D., Simard F., Andrade C., Angel D., Callier M., De Monbrison D., Fezzardi D., Haroun R., Harris A., Hughes A., Massa F., Roque E., Soto D., Marino G. (2017), Aquaculture and marine protected areas: potential for opportunities and synergies. Aquatic Conservation: 27(s1): 138-150.

Macias J.C., Avila Zaragozá P., Karakassis I., Sanchez-Jerez P., Massa F., Fezzardi D., Yücel Gier G., Franičević V., Borg J.A., Chapela Pérez R.M., Tomassetti P., Angel D.L., Marino G., Nhhala H., Hamza H., Carmignac C., Fourdain L. (2019), Allocated Zones for Aquaculture: a guide for the establishment of coastal zones dedicated to aquaculture in the Mediterranean and the Black Sea. General Fisheries Commission for the Mediterranean. Studies and Reviews. No 97. Rome, FAO: 90 pp.

Massa F. (2011), Some key aspects related to the social dimension of aquaculture. In: FOESA (2011). Sustainability indicators for aquaculture sea cages in the Mediterranean. 116 pp. FOESA, Madrid.

Massa F., Fezzardi D. (2021), Guidelines in support of Social Acceptability for aquaculture development. Deliverable 7.1 of the Horizon 2020 project MedAID (GA number 727315), published in the project web site on 22.02.2021: http://www.medaid-h2020.eu/index.php/deliverables/

Massa F., Onofri L., Fezzardi D. (2017), Aquaculture in the Mediterranean and Black Sea: a Blue Growth perspective. In: P.A. NUNES, L.E. SVENSSON, MARKANDYA A. (Eds.) Handbook on the Economics and Management of Sustainable Oceans, $1^{\text {st }}$ edition, 624 pp. UK, Edward Elgar Publishing, Cheltenham.

Nenciu M.I. Niţă V., Țoțoiu A., Hamza H. (2020), Framework for setting-up a classification and monitoring program for shellfish at the Romanian Black Sea coast. J Environ Prot Ecol, 21 (1): 184-192.

Nicolae C.G., Ișfan N., Bahaciu G.V., Marin M.P., Moga L.M. (2016), Case study in traceability and consumer's choices on fish and fishery products. AgroLife Scientific Journal: 5(2): 103-107.

Niţă V., Massa F., Nicolaev S., Fourdain L., Nenciu M.I. (2020), Establishing the suitability of the Agigea - Eforie area for designation as Allocated Zone for Aquaculture (AZA) and for unlocking the potentiality of mariculture in Romania. Cercetări Marine/Recherches Marines: 50: 152-173.

ROMPOP (2014). Market survey for the fisheries sector. Technical support for the development and consolidation of the institutional capacity of the Management Authority in order to elaborate and prepare the implementation of Operational Programme for Fisheries and Maritime Affairs 2014-2020: 424 pp. 
Rubstello K. (2019), The social acceptability of shellfish aquaculture in Washington. Master Thesis, University of Rhode Island (USA): 100 p., https://digitalcommons.uri.edu/theses/1474

Sanchez-Jerez P., Karakassis I., Massa F., Fezzardi D., Aguilar- Manjarrez J., Soto D., Chapela R., Avila P., Macias J.C., Tomassetti P., Marino G., Borg J.A., Franicevic V., Yucel-Gier G., Fleming I.A., Biao X., Nhhala H., Hamza H., Forcada A., Dempster T. (2016), Aquaculture’s struggle for space: the need for coastal spatial planning and the potential benefits of Allocated Zones for Aquaculture (AZAs) to avoid conflict and promote sustainability. Aquaculture Environment Interactions: 8: 41-54.

Stancu V., Brunsø K., Peral I., Santa-Cruz E., Alfaro B., Krystallis A., Guerrero L. (2018), Report on market segmentation: Identification of market niches for different consumer profiles of fish products. Deliverable 5.2 of the Horizon 2020 project MedAID (GA number 727315), published in the project website on 19.10.2018: http://www.medaidh2020.eu/index.php/deliverables/

Thomas J-B., Nordström J., Risén E., Malmström M., Gröndahl F. (2018), The perception of aquaculture on the Swedish West Coast. Ambio: a Journal of Human Environment: 47(4):398-409: https://doi.org/10.1007/s13280017-0945-3.

Zaharia T., Ursache C., Alexandrov L., Crivăţ M. (2005), Tendencies of the Romanian market regarding the consumers' perception of oysters. Annals of the "Lower Danube“" University of Galati: VI : 67-72. 